Bioscientia Medicina: Journal of Biomedicine $\&$ Translational Research

Journal Homepage: www.bioscmed.com

\title{
Efficacy of Lidocaine and Ketamine Combination on Reduction of Pain Intensity, Improvement of Functional State and Central Desensitization of Chronic Low Back Pain
}

\author{
Henry Sugiharto $^{1^{*}}$, Hasnawi Haddani ${ }^{1}$, Yuki Fitria ${ }^{1}$, Rizal Zainal$^{2}$ \\ ${ }^{1}$ Department of Neurology, Faculty of Medicine, Universitas Sriwijaya, Palembang, Indonesia \\ ${ }^{2}$ Department of Anesthesiology, Faculty of Medicine, Universitas Sriwijaya, Palembang, Indonesia
}

\author{
A R T I C L E I N F O \\ Keywords: \\ Ketamine \\ Lidocaine \\ Low back pain \\ Hyperalgesia \\ Central nervous system \\ Sensitization
}

\author{
Corresponding author: \\ E-mail-address: \\ dr_henry_sugiharto@yahoo.com \\ (Henry Sugiharto) \\ All authors have reviewed and \\ approved the final version of the
} manuscript.

https://doi.org/10.32539/bsm.v4i4.167

\begin{abstract}
A B S T R A C T
Introduction. Chronic low back pain (LBP) prevalence is approximately $20 \%$ of the world population. Central and peripheral sensitization is considered as the primary mechanism of pain chronification. This study hypothesizes that lidocaine and ketamine combination reduces pain intensity, improves functional state and central desensitization of chronic low back pain. It is by modulating central sensitization in sub-anaesthetic dose, prolonging inactivation of Na-channel, blocking NMDAreceptor and preventing secondary hyperalgesia. This study aimed to evaluate the efficacy of lidocaine and ketamine combination on the intensity of pain, functional state and central desensitization of chronic low back pain.
\end{abstract}

Methods. This double-blind, randomized control trial study was carried out in Mohammad Hoesin General Hospital, Palembang, Indonesia from May 2018 to January 2019. A total of 20 patients with low back pain that last for more than three months, aged more than 18 years old, of either sex who were willing to be enrolled in this study, were randomly allocated into one of the two groups of 10 each. The treatment group $(\mathrm{n}=10)$ received standardized therapy (analgesic and physiotherapy) + intravenous ketamine $0.5 \mathrm{mg} / \mathrm{kg}+$ lidocaine $2 \mathrm{mg} / \mathrm{kg}$ and the control group $(n=10)$ received standardized therapy $+100 \mathrm{ml}$ Nacl $0.9 \%$. Pain intensity, functional state, and central desensitization were measured before the treatment, day seven after treatment, and a month after treatment using Numeric Pain Rating Scale (NPRS), Functional Pain Scale (FPS), and Central Sensitization Inventory (CSI).

Results. The administration of ketamine $0.5 \mathrm{mg} / \mathrm{kg}+$ lidocaine $2 \mathrm{mg} / \mathrm{kg}$ resulted in NPRS and CSI changes was effective since the $7^{\text {th }}$ post-interventiontion $(p-$ value $=0.021$ and $p$-value $=0.001)$ while on FPS changes, it was effective since the $30^{\text {th }}$ post-interventiontion ( $p$-value $=0.000$ )

Conclusion. From the result, it could be concluded that the administration of ketamine and lidocaine is effective in decreasing pain intensity and central desensitization in chronic LBP.

\section{Introduction}

Central and peripheral sensitization is considered as the most critical mechanism that contributes to pain chronification. Ketamine, a noncompetitive N-methyl-D-aspartate (NMDA), acts as a specific NMDA blocker and modulate central sensitization in subanesthetic dose.1,2,3 Lidocaine effects by prolonging inactivation of the sodium channel, blocking NMDA receptor and preventing secondary hyperalgesia. 1,2,3 The International Associations for The Study of Pain defines pain as an unpleasant sensory and emotional experience associated with actual or potential tissue damage or 
described in terms of such cost. ${ }^{4}$ Generally, patient continuously experiences chronic low back pain even though the source of the pain is found and treated. This type of pain last more than a month or year even after threading cause of the pain has been resolved. 5 Pain prevalence in Indonesia has yet to be a stud. Still, it is estimated that the incidence of rheumatic pain is about $23.6-31.3 \%$, low back pain is about $40 \%$ of all population, with the prevalence of male and female are $18,2 \%$ and $13,6 \%$ respectively. A trial by a group of pain researchers in 14 hospital's outpatient multicenter during May 2002, found that $25 \%$ of all visits during that month were pain-related cases with a total of 4465 patients.

According to WHO, opioid is the first line to treat persistent to severe pain. The opioid can be used temporarily to control severe pain, but not for prolonged use. When given in a larger dose opioid may cause side effects which later can affect the process of rehabilitation. 5

The development of science and technology with the inventions of newer analgesics, provide a unique combination with a multimodal concept to treat pain, including the use of ketamine and lidocaine. Ketamine is used as an analgesic for acute and chronic low back pain in sub anaesthetic dose; it blocks specific NMDA and modulates central sensitization, therefore creating an antihyperalgesic effect. 1,2,3 After intravenous administration, distribution volume almost reach $3 \mathrm{~L} / \mathrm{kg}$ with $7-15$ minutes of redistribution half time, $15 \mathrm{ml} / \mathrm{kg}$ clearance, and 2-3 hours of elimination half time. Ketamine rapidly crosses the blood-brain barrier. Lidocaine acts by prolonging sodium channel inactivation, blocking NMDA receptor and preventing secondary hyperalgesia.1,2,3 Lidocaine protein binding is $70 \%$, its lipid solubility is 2,9 ; with onset 4-6 minutes, and duration of action 45-90 minutes (hyperbaric) and 60-117 minutes (isobaric).

It is hypothesized that this combination of therapy can produce a rapid analgesic effect with long duration of pain relief due to its impact on central and peripheral sensitization. So, this study aims to evaluate the effectiveness of lidocaine and ketamine combination on the intensity of pain, functional state and central desensitization of chronic low back pain by using Numeric Pain Rating Scale (NPRS), Central Sensitization Inventory (CSI) and Functional Pain Scale (FPS) before and after the administration of lidocaine and ketamine.

\section{Methods}

An add-on randomized controlled trial (RCT) has been done in Mohammad Hoesin General Hospital from May 2018 to January 2019. Health Research Review Committee of Mohammad Hoesin Central Hospital and Sriwijaya University declares that proposal health research is ethically liable (N0.88/kepkrsmhfkunsri/2018). Twenty subjects with chronic low back pain who met the inclusion criteria were included in the study. Ten subjects from treatment group are given the standardized therapy (analgesic and physiotherapy) + infusion of ketamine $0.5 \mathrm{mg} / \mathrm{kg}$ and lidocaine $2 \mathrm{mg} / \mathrm{kg}$ and ten subjects from placebo group are given graded therapy + injection of $100 \mathrm{ml} \mathrm{NaCl} \mathrm{0.9 \% .}$

Lidocaine-ketamine protocol for chronic non-cancer pain desensitization (Sriwijaya Protocol)

1. Patients selection

The target of this protocol is for patients with at least three months of chronic non-cancer pain. Chronic non-cancer pain that we have successfully treated includes chronic headache (e.g. chronic migraine, chronic tension-type headache, medication-overuse headache and chronic myofascial pain syndrome), chronic musculoskeletal pain (e.g. chronic low back pain) and chronic neuropathic pain (e.g.post-strokes central pain, painful diabetic neuropathy). Always assess all patients for numeric rating scale (NRS), central sensitization inventory (CSI) and functional pain scale (FPS) to get their baseline and evaluate progress.

2. Perform ECG 
ECG is needed to exclude heart block pattern, which is the absolute contraindication for intravenous lidocaine.

3. MeasureIntraa ocular pressure

Use tonometry to measure patients' intraocular pressure (pressure should not exceed $20 \mathrm{mmHg}$ - this procedure aimed to screen patients with increased intraocular demand because ketamine might potentially increase intraocular strength.

4. Manage blood pressure

Patient with a history of hypertension should be under medication control, and blood pressure should not exceed pre-hypertension or systolic pressure not more than $139 \mathrm{mmHg}$. Because ketamine itself would increase blood pressure, we prefer patient in the pre-hypertensive state to avoid the undesirable side effect

5. Perform skin test

Skin test of lidocaine and ketamine to identify the risk of allergy or anaphylactic shock (although it is scarce)

6. Pre-infusion medication Administer midazolam IV of 2.5-3 mg for premedication to counter the effect of hallucination by ketamine. This is done before the infusion of lidocaine-ketamine. On some patients, the hallucination effect will still take place, but it is not an indication to stop the procedure.

7. The infusion

Doses of lidocaine $2 \%$ are between $2-5 \mathrm{mg} / \mathrm{kg}$ BW and doses of ketamine is between 0.2$0.5 \mathrm{mg} / \mathrm{kg}$ BW. Both medications will be diluted in 100cc of normal saline and be entirely infused in 30-45 minutes. Start low go slow on the dosing is advised (provided patients need re-infusion).

8. Intra-infusion monitoring Attach a vital sign monitor if the patient is being infused for the first time to observe any significant changes. Stop the procedure if patients' blood pressure exceed stage I hypertension (systolic over $159 \mathrm{mmHg}$ ) or heart block occurred on ECG.

9. Re-assessment post-infusion

Re-assess patients NRS directly postinfusion and NRS, CSI and FPS 1-week postinfusion. In some patients, the effect might take place 2-3 days after infusion.

10. Reinfusion consideration

Reinfusion is advised if there is an improvement on NRS, CSI and FPS after 1week post-infusion while clinicians' judgement of patients is also being taken into account. Intervals might vary, but in our institution, we re-infuse on the 1-week interval.

11. Medication post-infusion

All pain medication before infusion should be selectively continued post-infusion. We prescribe membrane stabilizers like gabapentin or pregabalin in monotherapy or combination with tricyclic antidepressants like amitriptyline. Evaluate dosing for tolerability if titration is needed.

\section{Inclusion Criteria}

- $\quad$ Age $>18$ years old

- All the patients with chronic low back pain that last more than three months

- Patients who give consent to participate in this study

\section{Exclusion Criteria}

- A condition with signs of elevated intracranial pressure

- A state with symptoms of high intraocular pressure

- A patient who underwent surgery or pain intervention management for the past three months before the study

- Liver dysfunction

- Pregnancy and lactation 
- History of ketamine or lidocaine allergic reaction

- History of psychiatry problems

- Cancer pain

- Arrhythmia

Subjects were randomly allocated into two groups by one of the authors using computerized randomization. Procedures were managed by one of the other authors that are blinded from the group allocation, and subjects were also blinded. Pretreatment, on the $7^{\text {th }}$ day after treatment and 30th day after treatment, patients were evaluated for their pain scale, functional scale, and central sensitization by the author who did the procedures as well.

\section{Results}

General characteristics of respondents showed no difference in age, sex, occupation, and duration of pain between the two groups while education was significantly different between the two groups. Statistical test results obtained age $p$-value $=0.936$, sex $p$-value $=0.650$, occupation $p$-value $=0.274$, and pain duration $p$-value $=0.301$ between the two groups $(p>0.05)$ while education $p$-value $=0.028$ $(p<0.05)$. Tables 1 .

The results of the homogeneity analysis test for baseline pain which consisted of NPRS, CSI and FPS variables showed a statistical analysis of $p$-values of each NPRS ( $p$-value $=0.245)$, CSI $(p$-value $=0.715)$, and FPS $(p$-value $=0.523)(\mathrm{p}>0.05)$ which means that there was no significant difference in the scores of the NPRS, CSI and FPS between two groups at the beginning of the study (baseline). Tables 2 .

Based on a statistical analysis of differences in NPRS in the treatment group, it was found that there was no difference in NPRS before and on the $7^{\text {th }}$ day after the intervention ( $p$-value $=0.285)$, before and on the 30th day after the intervention $(p$-value $=0.088)$ and between the $7^{\text {th }}$ day after the intervention and the $30^{\text {th }}$ day after an intervention $(p$-value $=0.172)$. In the placebo group, it was found that there was no difference in NPRS before and on the $7^{\text {th }}$ day after an intervention ( $p$-value $=0.285$ ), on the 30th day after an intervention ( $p$-value $=0.088)$. However, there was a significant difference in the NPRS on the $7^{\text {th }}$ day after the intervention compared to the $30^{\text {th }}$ day after the intervention ( $p$-value $=0.022)$.

The results of effectivity analysis of $0.5 \mathrm{mg} / \mathrm{kg}$ + ketamine lidocaine with $2 \mathrm{mg} / \mathrm{kg}$ of ketamine to NPRS showed a significant difference in the NPRS means between the $7^{\text {th }}$ day and $30^{\text {th }}$ day after intervention between the treatment and placebo group. This means that the administration of ketamine $0.5 \mathrm{mg} / \mathrm{kg}$ + lidocaine $2 \mathrm{mg} / \mathrm{kg}$ resulted in NPRS changes has been active on the $7^{\text {th }}$ day after intervention. The complete analysis results are presented in the following table 3.

Based on a statistical analysis of CSI differences in the treatment group, it was found that there were significant differences in CSI before and on the $7^{\text {th }}$ day after intervention $(\mathrm{p}=0,000)$, before and on the $30^{\text {th }}$ day after intervention $(p$-value $=$ $0,000)$ and between the $7^{\text {th }}$ day and the $30^{\text {th }}$ day after intervention $(p$-value $=0.015)$. Whereas in the placebo group, there was no significant difference in CSI before and on the $7^{\text {th }}$ day after a response $(p$ value $=0.841$ ), before and on the $30^{\text {th }}$ day after an intervention ( $p$-value $=0.443)$ but there was a significant difference in CSI on the $7^{\text {th }}$ day after the response compared to the $30^{\text {th }}$ day after an intervention ( $p$-value $=0.209)$.

The results of the effectivity analysis of 0.5 $\mathrm{mg} / \mathrm{kg}$ of ketamine $+2 \mathrm{mg} / \mathrm{kg}$ of lidocaine to CSI found that on $7^{\text {th }}$ day and $30^{\text {th }}$ day, there was a significant difference in CSI mean between the treatment and placebo group. This means that the administration of ketamine $0.5 \mathrm{mg} / \mathrm{kg}+$ lidocaine 2 $\mathrm{mg} / \mathrm{kg}$ resulted in CSI changes has been active since the $7^{\text {th }}$ day. The complete analysis results are presented in the following table 4.

Based on a statistical analysis of FPS differences in the treatment group, it was found that there were significant differences in FPS before and on the $7^{\text {th }}$ day after intervention $(p$-value $=0.024)$, 
before and on the $30^{\text {th }}$ day after a response $(p$-value $=$ $0.004)$ and between the $7^{\text {th }}$ day and the $30^{\text {th }}$ day after an intervention ( $p$-value $=0.024)$. Whereas in the placebo group, it was found that there was a significant difference in FPS before and on the 7 th day after an intervention ( $p$-value $=0.025$ ), but there was no significant difference in FPS before and on the 30 th day after intervention $(p$-value $=0.083)$ neither between the $7^{\text {th }}$ day and $30^{\text {th }}$ day after an intervention $(p$-value $=0.317)$.

The results of effectivity analysis of ketamine $0.5 \mathrm{mg} / \mathrm{kg}$ + lidocaine $2 \mathrm{mg} / \mathrm{kg}$ in FPS found that on the $7^{\text {th }}$ day, there was no significant difference in FPS mean between the treatment and placebo groups. In contrast, on the $30^{\text {th }}$ day, there was a significant difference between treatment and placebo group in FPS mean, meaning that the administration of 0.5 $\mathrm{mg} / \mathrm{kg}$ of ketamine $+2 \mathrm{mg} / \mathrm{kg}$ of lidocaine resulted in FPS changes has been active since the $30^{\text {th }}$ day. The complete analysis results are presented in the following table 5 .

Table 1. Demographic profile

\begin{tabular}{|c|c|c|c|}
\hline \multirow[b]{2}{*}{ Characteristic } & \multicolumn{2}{|c|}{ Group } & \multirow[b]{2}{*}{$p$-value } \\
\hline & $\begin{array}{c}\text { Treatment }(\mathbf{n}=10) \\
n(\%)\end{array}$ & $\begin{array}{c}\text { Placebo (n=10) } \\
\text { n (\%) }\end{array}$ & \\
\hline Age (years), mean \pm SD & $52,50 \pm 10,65$ & $52,10 \pm 11,18$ & 0,936 a \\
\hline $\begin{array}{ll}\text { Sex } & \\
\text { - } & \text { Male } \\
\text { - } & \text { Female }\end{array}$ & $\begin{array}{l}3(30,0) \\
7(70,0)\end{array}$ & $\begin{array}{l}5(50,0) \\
5(50,0)\end{array}$ & $0,650 \mathbf{b}$ \\
\hline $\begin{array}{l}\text { Age Classification } \\
\begin{aligned} & \text { - } \\
\text { - } & >50-50 \text { years old } \\
& \text { years old }\end{aligned}\end{array}$ & $\begin{array}{c}3(3,0) \\
7(70,0)\end{array}$ & $\begin{array}{l}5(50,0) \\
5(50,0)\end{array}$ & $0,650 \mathbf{b}$ \\
\hline $\begin{array}{l}\text { Occupation } \\
\text { - } \text { Housewife } \\
\text { - } \text { Private employee } \\
\text { - Entrepreneur } \\
\text { - } \text { Government employee } \\
\text { - } \text { Pensionary }\end{array}$ & $\begin{array}{l}7(70,0) \\
1(10,0) \\
1(10,0) \\
0(0) \\
1(10,0)\end{array}$ & $\begin{array}{c}5(50,0) \\
4(40,0) \\
0(0) \\
1(10,0) \\
0(0)\end{array}$ & $0,274 \mathbf{b}$ \\
\hline $\begin{array}{c}\text { Educational background } \\
\text { - } \text { Elementary school } \\
\text { - Junior high school } \\
\text { - High school } \\
\text { - Diploma/bachelor }\end{array}$ & $\begin{array}{c}0(0) \\
2(20,0) \\
6(60,0) \\
2(20,0)\end{array}$ & $\begin{array}{l}5(50,0) \\
3(30,0) \\
1(10,0) \\
1(10,0)\end{array}$ & $0,028 \mathbf{b}$ \\
\hline $\begin{array}{l}\text { Pain duration } \\
\begin{aligned} \bullet & <1 \text { year } \\
\bullet & 1-3 \text { years } \\
\bullet & >3 \text { years }\end{aligned}\end{array}$ & $\begin{array}{l}2(20,0) \\
4(40,0) \\
4(40,0)\end{array}$ & $\begin{array}{c}0(0) \\
4(40,0) \\
6(60,0)\end{array}$ & $0,301^{\mathbf{b}}$ \\
\hline
\end{tabular}


Table 2. Baseline pain between group

\begin{tabular}{|c|c|c|c|c|}
\hline \multirow{2}{*}{ Baseline Pain } & \multicolumn{2}{|c|}{ Groups } & \multicolumn{2}{|c|}{$\begin{array}{c}\text { Levene's test for equality of } \\
\text { variances }\end{array}$} \\
\hline & $\begin{array}{c}\text { Treatment } \\
(\mathbf{n}=10)\end{array}$ & $\begin{array}{c}\text { Placebo } \\
(n=10)\end{array}$ & $\mathbf{F}$ & Sig. \\
\hline NPRS & $3,30 \pm 1,160$ & $4,80 \pm 1,68$ & 1,442 & 0,245 \\
\hline CSI & $33,20 \pm 9,15$ & $36,00 \pm 9,42$ & 0,138 & 0,715 \\
\hline FPS & $2,40 \pm 0,51$ & $2,40 \pm 0,69$ & 0,424 & 0,523 \\
\hline
\end{tabular}

Table 3. The effectivity of ketamine $0.5 \mathrm{mg} / \mathrm{kg}+$ lidocaine $2 \mathrm{mg} / \mathrm{kg}$ administration based on $\mathrm{NPRS}$

\begin{tabular}{lccccc}
\hline Time & Treatment & $\boldsymbol{p}$-value & $\begin{array}{c}\text { Placebo } \\
\text { Mean } \pm \text { SD }\end{array}$ & $\boldsymbol{p}$-value* & $\boldsymbol{p}^{*-v a l u e^{* *}}$ \\
\hline Bean \pm SD & & $4,80 \pm 1,68$ & $0,373^{\mathrm{b}}$ & $0,02^{\mathrm{c}}$ \\
Day 7 & $3,30 \pm 1,16$ & $0,285^{\mathrm{a}}$ & $4,40 \pm 0,96$ & & $0,002^{\mathrm{d}}$ \\
\hline Baseline & $2,60 \pm 1,95$ & & $4,80 \pm 1,68$ & $0,373^{\mathrm{b}}$ & - \\
Day 30 & $3,30 \pm 1,16$ & $0,088^{\mathrm{b}}$ & $5,20 \pm 1,13$ & & $0,022^{\mathrm{b}}$ \\
\hline Day 7 & $1,50 \pm 2,22$ & & & & -
\end{tabular}

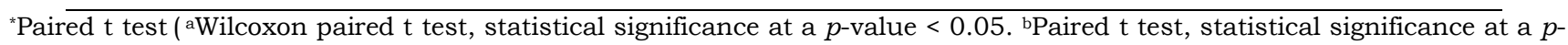
value $<0.05$ ), ${ }^{* *}$ Independent $\mathrm{t}$ test ('Independen $\mathrm{t}$ test, statistical significance at a $p$-value $<0.05$, dMann Whitney $\mathrm{U}$, statistical significance at a $p$-value $<0.05)$.

Table 4. The effectivity of ketamine $0.5 \mathrm{mg} / \mathrm{kg}+$ lidocaine $2 \mathrm{mg} / \mathrm{kg}$ administration based on CSI

\begin{tabular}{lccccc}
\hline Time & $\begin{array}{c}\text { Treatment } \\
\text { Mean } \pm \text { SD }\end{array}$ & $\boldsymbol{p}$-value & $\begin{array}{c}\text { Placebo } \\
\text { Mean } \pm \text { SD }\end{array}$ & p-value* & $\boldsymbol{p}^{\text {-value ** }}$ \\
\hline Baseline & $33,20 \pm 9,15$ & $0,000^{\mathrm{a}}$ & $36,0 \pm 9,42$ & $0,841^{\mathrm{b}}$ & $0,001^{\mathrm{c}}$ \\
Day 7 & $20,40 \pm 9,53$ & & $35,70 \pm 6,76$ & & $0,000^{\mathrm{d}}$ \\
\hline Baseline & $33,20 \pm 9,15$ & $0,000^{\mathrm{a}}$ & $36,0 \pm 9,42$ & $0,443^{\mathrm{b}}$ & - \\
Day 30 & $13,20 \pm 7,78$ & & $37,20 \pm 6,87$ & & $0,209 \mathrm{~b}$ \\
\hline Day 7 & $20,40 \pm 9,53$ & $0,015^{\mathrm{b}}$ & $35,70 \pm 6,76$ & &
\end{tabular}

${ }^{*}$ Paired $\mathrm{t}$ test (aWilcoxon paired t test, statistical significance at a $p$-value $<0.05$. ${ }^{b}$ Paired t test, statistical significance at a $p$-value $<0.05$ ), ${ }^{* *}$ Independent $\mathrm{t}$ test (cIndependen $\mathrm{t}$ test, statistical significance at a $p$-value $<0.05$, dMann Whitney $\mathrm{U}$, statistical significance at a $p$-value $<0.05)$. 
Table 5. The effectivity of ketamine $0.5 \mathrm{mg} / \mathrm{kg}+$ lidocaine $2 \mathrm{mg} / \mathrm{kg}$ administration based on FPS

\begin{tabular}{|c|c|c|c|c|c|}
\hline Time & $\begin{array}{c}\text { Treatment } \\
\text { Mean } \pm \text { SD }\end{array}$ & $p$-value & $\begin{array}{c}\text { Placebo } \\
\text { Mean } \pm \text { SD }\end{array}$ & $p$-value* & $p$-value ** \\
\hline Baseline & $2,40 \pm 0,51$ & $0,024^{a}$ & $2,40 \pm 0,69$ & $0,025^{a}$ & \\
\hline Day 7 & $1,50 \pm 0,70$ & & $1,90 \pm 0,73$ & & $0,353^{d}$ \\
\hline Baseline & $2,40 \pm 0,51$ & $0,004^{a}$ & $2,40 \pm 0,69$ & $0,083^{a}$ & \\
\hline Day 30 & $0,60 \pm 0,69$ & & $2,10 \pm 0,56$ & & $0,000^{d}$ \\
\hline Day 7 & $1,50 \pm 0,70$ & $0,024^{a}$ & $1,90 \pm 0,73$ & $0,317^{a}$ & \\
\hline Day 30 & $0,60 \pm 0,69$ & & $2,10 \pm 0,56$ & & \\
\hline
\end{tabular}

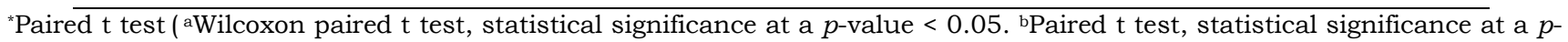
value $<0.05$ ), ${ }^{* *}$ Independent $\mathrm{t}$ test ('Independen $\mathrm{t}$ test, statistical significance at a $p$-value $<0.05$, dMann Whitney $\mathrm{U}$, statistical significance at a $p$-value $<0.05)$.

\section{Discussions}

The improvement in NPRS is related to the mechanism of action of ketamine as NMDA antagonist and lidocaine as local anaesthesia that acts as a sodium channel blocker. Ketamine has an analgesic effect centrally as well as peripherally, which is mediated by several receptors and channels, in particular hyperpolarization-activated cyclic nucleotide-gated cationic (HCN) channels that express the HCN1 subunit. Ketamine also inhibits serotonin and dopamine reuptake and inhibits voltage-gated sodium and potassium channels that have constant voltage.

NMDA receptors are activated by glutamate excitatory neurotransmitter and are known to influence many forms of neuroplasticity, in the short term as well as long time. With this mechanism, NMDA receptor, NMDA antagonist and ketamine, may play a role in the chronic low back pain pathway. Ketamine is classified as NMDA ( $N$-methyl-D-aspartic acid) receptor antagonist and can bind to opioid $\mu$ receptor and sigma receptor. Ketamine and noncompetitive nonactive ketamine metabolite are the antagonists of the NMDA receptor. NMDA antagonist may cause symptoms of opioid withdrawal, inhibit NMDA, and increase other receptors activity. 6,7,8,9,10 After intravenous administration with volume distribution approximate litres $/ \mathrm{kg}$, the redistribution time is 7 to 15 minutes, clearance millilitres $/ \mathrm{kg} /$ minute and a half-life elimination 2-3 hours. Ketamine rapidly passes the blood-brain barrier. In terms of ketamine use for long term therapy to ease chronic low back pain, the onset of the half-life of ketamine exceeds its half-life. ${ }^{7}$

Lidocaine works by inhibiting sodium channel. Thus no conduction and automatization occur. Lidocaine protein binding capability is $70 \%$, lipid solubility is 2.9 , and onset 4-6 minutes, with a duration of action 45-90 minutes on the hyperbaric condition and 60-117 minutes on isobaric condition. ${ }^{11,12,13}$ Voltage-Gated Sodium Channel (VGSC) is a complex transmembrane protein that allows rapid sodium influx which is the core of action potential depolarization in the excitatory cell which consist of one big $\alpha$ subunit and two small $\beta$ subunits.

Local anaesthesia binds to specific $\alpha$ subunit and inhibits voltage-gated sodium channel, prevents channel activation and inhibits the influx, which is related to membrane depolarization. Local anaesthesia which binds to sodium channel does not change resting membrane potential. With the increased concentration of local anaesthesia, an increase of sodium channel fraction on membrane occurs, restricts local anaesthesia molecule and inhibits sodium ion conduction. This results in the slowing of impulse, a decrease of an action potential, while excitatory threshold and impulse conduction increase progressively. Neuron sensitivity towards local anaesthesia inhibition depends on axon diameter, myelination, and anatomical and 
physiological factors. ${ }^{14,15,16,17,18}$

In terms of central sensitization, lidocaine showed antihyperalgesic periphery effect on bodily pain and primary impact on neuropathic pain, which results in fundamental hyperexcitability blockage. ${ }^{14,15,16,17,18,19}$. A dosage below $5 \mathrm{mg} / \mathrm{kg}$ that is given slowly (30 minutes), under monitoring, is considered safe. ${ }^{1,11}$

Central sensitization is considered the most important mechanism of pain, which contributes towards chronic musculoskeletal pain, chronic neuropathic pain, and chronic cephalgia. ${ }^{20.21}$ Among the theories that explain the process of central sensitization are the Wind Up theory, which shows the primary spinal mechanism in which continuous stimulation will cause temporal slowing and will create increased pain intensity. ${ }^{20}$ The NMDA that was once inactivated in reasonable condition because the existence of $\mathrm{Mg} 2+$ that closes the receptor, is now activated. NMDA plays a role in neuroplasticity process in chronic low back pain or pathologic pain. This leads to a mechanism that facilitates increased pain.

Literature showed that there was a change in descending pathway inhibition that comes from periaqueductal grey matter and rostral ventral medulla of the brain stem. Inhibition from falling pathway plays a role in neuron excitation focus on dorsal root ganglion, to produce a nociceptive signal that pushes, localized, and rapid towards biological relevant trigger impulse, which will suppress surrounding neuronal activity. Injury of one or more of a component of this inhibition system will result in central sensitization.22,23,24 Administration of a combination of ketamine (as NMDA antagonist) and lidocaine (that works by reducing direct and indirectly post-synaptic depolarization mediated by NMDA and neurokinin receptors) in this research proves to reduce central sensitization symptoms and results in a reduction of NPRS score. After one month of intervention, the pain was evaluated using NPRS of two research groups which resulted in different counts. Pain score in trial group decreased significantly than the placebo group. Compared to other studies, this combination of ketamine and lidocaine is more effective. The dosage of lidocaine used in this research was $2 \mathrm{mg} / \mathrm{kg} \mathrm{BW}$, lower than the dosage used in other studies. In this research, no repeat of administration was given compared to other previous investigations that had repetition. Until this research was reported, three subjects received adjuvant therapy of ketamine and lidocaine, said pain repeat on fifth and sixth month after the intervention. Thus, it may be concluded that the addition of a combination of ketamine $0.5 \mathrm{mg} / \mathrm{kg} \mathrm{BW}$ and lidocaine $\mathrm{kg}$ BW in standard therapy decreases pain score significantly and improve patients functional state. Standard treatment alone only reduces pain score on the first-week treatment, and score increases above baseline afterwards. The limitation of this research was the short follow-up period which results in the capability to show pain relapse in subjects that was given ketamine $\mathrm{kg} \mathrm{BW}$ $\mathrm{mg} / \mathrm{kgBW}+$ lidocaine $\mathrm{kg} \mathrm{BW} / \mathrm{kgBW}$.

The significant central nervous system (CNS) side effects of administration of ketamine were hallucination which can disturb subject and limit clinical usage. Other side effects include headache, fatigue, and a bad dream. Hallucination and dysphoria can be decreased by administration of benzodiazepine. In this research, administration of midazolam 0,05 mg/kg BW 15-minute prior infusion is useful to reduce hallucination. There were no significant side effects reported from the administration of ketamine and lidocaine during the study.

During the research study, Neurology Department of Sriwijaya University developed a lidocaine-ketamine protocol for chronic non-cancer pain desensitization. The contract is meant to systematically screen patients eligible for the infusion, thus increase the effectiveness and 
minimize the side effect.

\section{Conclusion}

Intravenous administration of ketamine and lidocaine was sufficient to reduce pain intensity, improve functional state and central desensitization on chronic low back pain with minimal post-infusion complication. Further research with a more prolonged period and larger sample are needed to establish its effectiveness and necessity of re-infusion further.

\section{References}

1. Rosenquist RW, Vrooman BM. Chronic Pain Management in Morgan \& Mikhail's Clinical Anesthesiology. 5th Edition. LANGE. 2013

2. Patri Murali. Sedation for Interventional Techniques. Essentials of Interventional Techniques in Managing Chronic Pain. Springer. 2018

3. Jurg Schliessbach and Konrad Maurer. Pharmacology of Pain Transmission and Modulation. Pain Medicine. Springer. 2017

4. Classification Of Chronic Pain. Descriptions Of Chronic Pain Syndromes And Definitions Of Pain Terms. Second Edition. International Association For The Study Of Pain. 2012

5. Barus Jimmy. Neuroanatomy dan Neurofisiologi Nyeri. Education Pain. Pustaka Bangsa Press. Medan. 2017

6. Guidelines for Pain Management Programmes for adults. An evidence-based review prepared on behalf of the British Pain Society. 2013

7. Alan D Kaye. Pharmacology. Anesthesiology Clinic. Volume 35. Elsevier 2017

8. Niesters et al. Ketamine for chronic pain: risk and benefits. British Journal of Clinical Pharmacology. 2013
9. Hanna et al. Intravenous Ketamine Produced Long-Term Pain Relief in a Patient with Fibromyalgia. J. Fibrom. 2016

10. Gorlin et al. Intravenous sub-anesthetic ketamine for perioperative analgesia. Journal of Anaesthesiology Clinical Pharmacology. 2016

11. Patil et al. Efficacy of Outpatient Ketamine Infusions in Refractory Chronic Pain Syndromes: A 5-Year Retrospective Analysis. Pain Medicine 2012; 13: 263-269. Wiley Periodicals, Inc.

12. Corporate Medical Policy. Intravenous Anesthetics for the Treatment of Chronic Pain. An Independent Licensee of the Blue Cross and Blue Shield Association. 2017

13. Christiansen et al. Chronic Pain: Pathophysiology and Mechanisms. Essentials of Interventional Techniques in Managing Chronic Pain. Springer. 2018

14. Hutson et al. Brief Research Article Intravenous Lidocaine for Neuropathic Pain: A Retrospective Analysis of Tolerability and Efficacy Pain Medicine 2014;

15. Kandil et al. Lidocaine Infusion: A Promising Therapeutic Approach for Chronic Pain. J Anesth Clin Res. 2017

16. Souza et al. The analgesic effect of intravenous lidocaine in the treatment of chronic pain: a literature review.Elsevier 2014

17. Wiley Blackwell. Evidence Based Chronic Pain Management. BMJ Books. 2010

18. Tania et al. Intravenous lidocaine for postmastectomy pain treatment: randomized, blind, plasebo controlled clinical trial. Elsevier. 2014

19. Gabriela Rocha Lauretti. Mechanisms of Analgesia of Intravenous Lidocaine. Rev Bras Anestesiol 2008; 58: 3: 280-286 
20. Dibyendunarayan D Bid. Central Sensitization In Chronic Low Back Pain: A Narrative Review. Dean, Faculty of Medicine; School of Physiotherapy, RK University. 2016

21. Elena Filatova et al. Evidence of persistent central sensitization in chronic headaches: a multi-method study. J Headache Pain (2008) 9:295-300.

22. Julia R. Tanjung. Plastisitas Memicu Timbulnya Sensitivitas Pada Nyeri Inflamasi. Departemen Fisiologi, Fakultas Kedokteran Unika Atma Jaya. Damianus Journal Of Medicine; Vol.10 No.1 Februari 2011: Hlm. 31-35

23. Marijana Bosnar. Neuroplasticity Mechanisms In The Pathophysiology Of Chronic Pain. Department of Neurology, Sestre milosrdnice University Hospital Center. 2012

24. Clifford J Woolf. Central sensitization: Implications for the diagnosis and treatment of pain. Program in Neurobiology and FM Kirby Neurobiology Center, Children's Hospital Boston, and Department of Neurobiology, Harvard Medical School, Boston. 2011 